\title{
Build Back Better: Leadership for US-Cuba Health Cooperation
}

As members of the global public health community, we thought the outgoing Trump administration in Washington could not do much else to shock us. But when President Biden revealed that his predecessor had left him not with a bad plan to tackle the COVID-19 pandemic - but with no plan at all-we were appalled, contemplating the nearly 100 million infected throughout the world, and the over 400,000 dead in the USA alone. It is no wonder that Dr Anthony Fauci, Biden's chief medical advisor and member of the coronavirus task force, told the press that he felt liberated now that science was back in the driver's seat. "Everything we do," he said of the new administration's approach, "is based on science and evidence."

If that is the case, then the US president's coronavirus task force should heed advice on the global cooperation urgently needed to stem the pandemic, which goes beyond staying in WHO, and listen to Dr Fauci's own advice on health cooperation with Cuba. In MEDICC Review's April 2018 issue, he advocated for just that after visiting Havana, writing with colleagues: "(Joint) infectious disease research can provide a model for other US-Cuba scientific cooperation."

The Biden-Harris administration already has a framework for such collaboration in the two Memoranda of Understanding signed during the Obama presidency by US Secretary of Health and Human Services, Silvia Mathews Burwell and Cuban Minister of Public Health Roberto Morales Ojeda. The two documents provide a useful, practical blueprint for initiating cooperation beneficial to people in both countries and, indeed, the world.

The first MOU, signed in June 2016, built on the two governments' commitment to "deepen public health cooperation, focusing on communicable diseases including those caused by arboviruses such as Zika, dengue and chikungunya; as well as on the prevention and treatment of chronic non-communicable diseases, such as cancer."

The agreement intended to strengthen "collaboration in these and other scientific and health areas." It noted that first efforts would be aimed at a health cooperation strategy "to address shared priorities such as: communicable diseases, principally arboviruses, including Zika, dengue, and chikungunya; non-communicable diseases, such as cancer, diabetes, hypertension, mental health and substance abuse disorders, and others; healthcare systems and public health management; quality management and patient safety systems in hospitals and outpatient settings; exchange of health professionals; health security and international health regulations; public health emergency preparedness and response; biomedical research and development, clinical trials, and medical product regulation; health information technology and the flow of health data; human services; and aging." The second MOU, signed in October the same year, proposed collaboration on cancer control, including research, surveillance, monitoring and evaluation.

However, to clear the way to revitalizing these agreements-which were never rescinded in their entirety as far as we know-means stripping away some 200 additional restrictions on Cuba that were added to already onerous sanctions during the Trump-Pompeo era. These include everything from hindering remittances intended for Cuban families to blocking oil and other shipments, torpedoing Cuban small businesses with added banking restrictions and putting all Cuban hotels off-limits to US travelers. In a bizarre turn of events, with just a few days left in his term and facing a second impeachment-this time for inciting a white supremacist mob that overran the US Capitol-Trump, mindless of the irony, named Cuba a "state sponsor of terror," a designation with far-reaching effects. Currently, Cuban health and government authorities are forced to grapple not only with the pandemic itself but also with the economic and social fallout of this draconian move whose roots are imbedded in Florida's rightwing, not in Cuba.

MEDICC Review's publisher, MEDICC, decried the eleventh-hour decision, comparing Cuba's significantly better record of confronting the pandemic with the Trump administration's COVID-19 denialism, and emphasized the "thousands of Cuban health professionals volunteering to fight COVID-19 in 40 countries," while the White House was clinging to 'vaccine nationalism'. The rates of disease and death in the two countries beg comparison. To date, The New York Times tracker shows the United States with 7549 cases per 100,000 population, compared to 182 cases per 100,000 population in Cuba; the USA at 126 deaths per 100,000, compared to just 2 per 100,000 population in Cuba.

Sharing experiences, research and effective strategies to tackle the pandemic is why MEDICC Review is engaging in a series of US-Cuba virtual forums, involving experts in both countries. We held the first on December 16, 2020, co-sponsored by the University of Minnesota and organized jointly with its Schools of Nursing and Public Health. University President Joan Galen and Minnesota Senator Amy Klobuchar participated, as did specialists in epidemiology, clinical care and vaccine research.

"With so much at stake, we need to build on partnerships like this one to ensure that our medical communities are benefiting from the most up-to-date and best practices for treating and preventing coronavirus, especially given the relatively low number of cases and deaths in Cuba." - Sen. Amy Klobuchar of Minnesota closing the MEDICC Review-University of Minnesota virtual forum, December 16, 2020

COVID-19 is highlighted in this issue of MEDICC Review and featured in a Cuba's Women of Science roundtable with investigators at the National Medical Genetics Center. Their preliminary immunogenetics findings on SARS-CoV-2 viral behavior in Cuba also have implications for the four Cuban COVID-19 vaccine candidates now in clinical trials. We provide continuing coverage of Cuban health professionals' experience treating COVID-19 patients abroad in an interview with Dr Carlos R. Pérez, who headed the team that served in Lombardy, Italy at the height of the epidemic there. Robaina's global literature review focuses on COVID-19's potential for mother-to-child transmission; and Ruiz details the response of a Havana surgical hospital to the disease. Drs Saurabh and 
Shrivastava issue an appeal for enhanced disease surveillance worldwide in their Viewpoint.

As COVID-19 vaccine production and distribution are ramped up worldwide-raising added questions of equity and vaccine hesitancy-Cruz takes the long view on vaccine-attributable adverse events in Cuba's childhood immunization program for 13 diseases, carried out in the context of a universal health system.

Cuban biotech products are the subject of two original research papers: one on hepatitis B preventive and therapeutic vaccines, and another on nasally-administered Cuban erythropoietin for patients with Parkinson disease. Additional articles treat issues important for Alzheimer and lupus disease research, as well as non-alcoholic fatty liver disease and urolithiasis in children and adolescents. And a Perspective reviews experience with psychological care for heart patients.

Finally, an important paper looks at an underutilized therapy to save the lives of newborns suffering from hypoxic ischemic encephalopathy in Latin America.

In this issue, we also take the opportunity to thank our peer reviewers for their contribution to the journal in 2020.
We are not yet prepared to surrender to the idea that global scientific collaboration is impossible; that politics will invariably undermine research and development; that selfishness will always prevail over symbiosis.

-Viewpoint by Robert Cañete, Medical University of Matanzas, Cuba and Kenneth W. Goodman, University of Miami Miller School of Medicine

Moving into 2021-when overarching concerns of climate, planetary health and human survival must command our attention-we are struck by the lessons unlearned and unheeded by those who would lead us. In the case of the United States government and its over 60 years of nearly unbroken hostility towards Cuba, foregoing cooperation, we say enough. Basta. End the sanctions on Cuba. It's not too late to collaborate: COVID-19 has provided the urgency. Now all it takes is leadership. President Biden? - 14

The Editors 